\title{
Die samestelling en struktuur van die boek Hosea
}

W Vosloo

\begin{abstract}
The composition and structure of the book Hosea

Notwithstanding the composition of a book as revealed by means of historical critical methods, it is necessary to establish the structure of the final text by way of literary criteria and with regard to contents. Such a structure does not necessarily represent the intention of the author(s), but represents a reader's approach to the text. Most commentaries on the book of Hosea follow the main divisions 1-3; 4-11; 12-14, which has been demonstrated to be the result of formation and the final redactor's activities. A more viable structure is proposed to facilitate the reading of the text.
\end{abstract}

Die samestelling van 'n Bybelboek kan vanuit historiese hoek benader word, maar dan gaan dit om 'n redaksie-kritiese ondersoek en is die resultaat 'n beeld van die wording van die teks. Dit gee aan die leser 'n historiese greep op die teks. Om 'n greep op die teks as literatuur te kry ten einde die finale produk in sy geheel en in sy dele te ondersoek, moet formele merkers, saaklike verbande, kleiner versamelings en ander verdelende en samebindende aanduidings ook in ag geneem word.

Die struktuur van die boek Hosea lewer vir haas elke ondersoeker van die boek probleme op. Daar bestaan redelike eenstemmigheid oor die hoofverdeling as of ' $n$ tweedeling (1-3 en 4-14), of 'n driedeling (1-3, 4-11, 12-14). Werke van die afgelope dekades wat die tweedeling volg, is: Laetsch ${ }^{1}$, Frey $^{2}$, Rudolph $^{3}$, Mays ${ }^{4}$, en Andersen en Freedman's. Diegene wat 'n driedeling volg met somtyds 'n onderverdeling van 4-14, is: Wolff 6 , Van Leeuwen ${ }^{7}$, Deissler ${ }^{8}$, Jeremias ${ }^{9}$, Yee ${ }^{10}$ en Hubbard ${ }^{11}$. Wyrtzen ${ }^{12}$ verdeel die eerste hoofdeel in drie dele, Stuart ${ }^{13}$ werk net met perikope, en Beeby ${ }^{14}$ verdeel die tweede hoofdeel in twee dele.

Oor 1-3 is daar haas geen verskil van mening nie. Die groot probleem lê by 4-14. Mays ${ }^{15}$ sê dat 4-14 die duidelike planmatigheid van 1-3 mis en voeg by: "Here the collector is working simply to arrange the rest of the material available to him and he is using common themes and catchwords to organize it". So 'n opmerking is dalk begryplik wanneer probeer word om die saak vanuit die sender se oogpunt te verstaan. Dinge verander egter ietwat indien daar vanuit die leser se oogpunt na 'n sistematisering gesoek word wat as grondslag kan dien vir 'n makliker hantering van die teks. Maar selfs vanuit 'n leser se perspektief beskou, is daar steeds probleme wat 'n verantwoordbare indeling bemoeilik. In dié verband sê Stuart 16: "... the editorial arranging... is either so skillful or so nonchalant... as to result in a relative absence of sharp delineations between pericopes. In fact, deciding where one passage in Hosea leaves off and another begins has been a major consideration for every commentator and critic".

Samestelling op grond van oorlewerings- en redaksionele prosesse

Die driedeling is geen saaklike verdeling nie, maar hang saam met die totstandkoming van die boek. Reeds in die vorige eeu is 1-3 en 4-14 al as hoofdele 
onderskei. Wolff ${ }^{17}$ het egter aangetoon dat dit eintlik uit drie "Überlieferungskomplexe" bestaan (1:2-3:3; 4:1-11:11; 12:1-14:9) met $1: 1$ die inleiding en $14: 10$ die slot. Omdat dit oorleweringskomplekse is, hou dit bepaalde nadele in indien dit as struktuur vir die bestudering van die boek gebruik word. Vandaar dat Wolff self saaklike versamelings onderskei het.

In haar ondersoek na die redaksiegeskiedenis van die boek het Gale $A$ $\mathrm{Yee}^{18}$ tot die gevolgtrekking gekom dat die boek 'n baie ingewikkelde wordingsgeskiedenis beleef het. Sy onderskei vier stadia:

(1) Die oorspronklike Hoseaanse tradisie wat die kern vorm van al drie hoofklomplekse van die boek, maar net ongeveer $27 \%$ van die boek beslaan.

(2) Die stadium van die versamelaar wat kort na die val van Samaria die profesieë versamel het, sommige uitgebrei en gewysig het en die roeping van Hosea opnuut geskryf het. Hy was verantwoordelik vir dele van die eerste twee hoofstukke, maar dit is 'n skrale 5\% van die totaal.

(3) Die stadium van die eerste redaktor. Volgens Yee was hy 'n Judeër wat deurdrenk was van die Deuteronomistiese ideologie. Daarom het hy besondere klem gelê op die tora, die "afvallige" kultus van die Noordryk (die "sonde van Jerobeam"), en die Baäls as die "minnaars" van Israel. Hy het 'n band gehad met die skrywers van die eerste edisie van die Deuteronomistiese Geskiedwerk en het dalk as propagandis vir Josia se hervormingsbeleid opgetree. Die dele wat sy aan hierdie stadium toeken is ongeveer $19 \%$ van die boek.

(4) Die stadium van die tweede redaktor. Hy het ook in die Deuteronomistiese tradisie gestaan en was vir ingrypende redaksionele veranderings verantwoordelik - ongeveer $49 \%$ van die hele boek! Só ingrypend was sy toevoegings dat geen hoofstuk in die boek daaraan ontsnap het nie. Hierdie veranderings en invoegings het hy gedoen deur middel van 'n groot verskeidenheid literêre tegnieke. Die bestaande struktuur (Wolff se "Überlieferungskomplexe") is grotendeels die resultaat van sy redaksionele werk. Dit geld met name die inleiding (1:1) en die slot (14:10); en die afsluiting van elkeen van die drie oorleweringskomplekse met 'n heilsprofesie, naamlik 3:1-5, 11:1-11 en 14:2-9. Daarmee sou hy die motief van die terugkeer van die vrou/Israel na Jahwe toe geskep het en dit in die drie hoofkomplekse ingebou het. Die doel was om die lesers tot bekering aan te spoor.

Kritiek op Yee se redaksie-ondersoek wat soveel klem op die eksiliese finale redaktor ${ }^{19}$ lê, is nie hier ter sake nie. Wat van belang is, is dat hierdie resente ondersoek Wolff se driedeling bevestig. Yee self beskou haar werk as "the first analytical step in understanding the book's formation" 20 en nie as die finale ondersoek na die struktuur van die boek nie. Daarmee open sy die deur vir verdere onderverdeling van hierdie groot oorleweringskomplekse.

\section{Pogings tot onderverdeling}

Rudolph21 is huiwerig om 'n kronologie aan te wys, maar sê dat daar wel 'n saaklike saamhorigheid bestaan tussen $6: 7-2 ; 7: 3-7 ; 7: 8-16$ (na aanleiding van $6: 4$ ); tussen 
9:10-11:11 (historiese terugblik); en tussen hoofstukke 12 en 13 (ook historiese terugblik).

Benewens 1:2-3:5 onderskei Wolff ${ }^{22}$ die volgende kleinere versamelings:
4:1-5:7 - die kultus uit die laaste jare van Jerobeam II
5:8-9:10 - uit die tyd van die Siro-Efraimitiese Oorlog en die tyd kort daarna
9:11-12:15 - uit die stil periode voor en na Salmaneser V se troonsbestyging in $727 \mathrm{vC})$
13:1-14:1 - koning Hosea is reeds gevang
14:2-9 - kort voor die val van Samaria.

Op grond van die onderwerpe wat in hoofstukke 4-11 behandel word, onderskei Hubbard ${ }^{23}$ die volgende versamelings:

4:1-5:7

$5: 8-7: 17[5: 8-7: 16]$

8:1-9:6 [8:1-9:9] _ - kultus en koningskap tydens die Assiriese oorheersing

9:10-11:9 [9:10-11:11] - oor historiese gebeurtenisse.

Die laaste hoofdeel verdeel hy soos volg24:

$\begin{array}{lll}\text { 11:12-12:1 [Hebr:12:1-2] } & \text { - } & \text { Efraim en Juda nou } \\ \text { 12:2-14 [Hebr: } 12: 3-15] & - & \text { Jakob toe en nou } \\ \text { 13:1-16 [Hebr: } 13: 1-14: 1] & - & \text { Efraim toe en nou } \\ 14: 1-8 \text { [Hebr: } 14: 2-9] & - & \text { berou en herstel } \\ 14: 9 \text { [Hebr: } 14: 10] & - & \text { slotvermaning. }\end{array}$

Ofskoon die pogings tot sistematisering nie met mekaar klop nie, is daar tog 'n groot mate van ooreenkoms te bespeur ${ }^{25}$. Hierdie ooreenkomste kan as vertrekpunt dien vir 'n sistematisering op grond van literêre kriteria en inhoudelike verbande en verskille. Daarmee kan ' $n$ indeling gemaak word wat aan die leser van Hosea 'n beter greep op die teks gee.

'n Indeling van die boek Hosea

1. Die inleiding (1:1)

$1: 1$ is ' $n$ inleiding tot die hele boek. Dit bevestig die inhoud as woorde van Jahwe en skets aan die hand van die konings die historiese tydvak waarin die gebeurtenisse van die boek afspeel.

2. Die ontrou van Israel $(1: 2-3: 5)$

Oor 1:2-3:5 is daar algemene eenstemmigheid dat dit 'n eenheid vorm rondom die huwelikslewe van Hosea met die tema: Die ontrou van Israel. Dit bestaan uit vyf perikope: 
- God se herstel begin by die aartsvadertyd

- die terugwen van die vrou

- die nuwe verhouding begin by die verlowing

- die herstel van Hosea se huwelik.

1:2-9 stuur af op die opheffing van die verbond (1:8-9). Dit bestaan uit vier opdragte, naamlik om te trou en om bepaalde name aan sy drie kinders te gee. Elke opdrag bestaan uit vier elemente, naamlik 'n inleidende vertelling, 'n inleidingsformule wat begin met אמר, 'n opdrag, en 'n verduideliking wat begin met 7 , wat ongetwyfeld ' $n$ latere invoeging is, verleen' $n$ ander vorm aan hierdie opbou.

2:1-3 is 'n heilswoord wat die nuwe verhouding tussen God en Israel teken. Dit begin by die aartsvaderbeloftes (2:1a), en herbeleef die eenheid van vroeër en die uittog onder 'n Mosesfiguur. Die nuwe heilstyd word met die omkering van die onheilsname van die drie kinders versinnebeeld.

2:4-17 beskryf die pogings om die vrou weer tot inkeer te bring. Dis in die vorm van 'n regsgeding geskryf, met die verrassende wending aan die einde. $2: 18$ begin met ' $n$ nuwe inleidingsformule en 'n nuwe heilswoord. In die perikoop word die woord Iל drie keer gebruik. Die woord is egter nie skeidend nie, maar bindend deurdat dit telkens die wentelpunt van die subperikoop vorm ${ }^{26}$. Dit bestaan uit vier subperikope:

* 2:4-5, die dreigement van 'n egskeiding, met die 19 van vers 5 as die wentelpunt.

" 2:6-9, die isolasie van die vrou om haar te verhinder om haar "minnaars" te vind sodat sy weer na Jahwe toe sal terugkeer. Die wentelpunt is ל teen die einde van vers 7 .

* 2:10-15c, die wegneem van die landbouprodukte om die onmag van die vrugbaarheidsgode te toon, met $T$ į in vers 11 die wentelpunt. Die subperikoop word voorts afgegrens deur die "sy het nie geken" in vers 10 en "My het sy vergeet" in vers $15 \mathrm{c}$.

* 2:15c-17, die terugwen van die vrou deur haar na die מִ מִ te lei en tot haar "hart" te spreek. In hierdie geval vervul vers $15 c$ 'n dubbele funksie as afsluiting van die vorige perikoop en die begin van 'n nuwe perikoop 27 . Weer eens is ל̧ in vers 16 die wentelpunt.

2:18-25 is ' $n$ heilswoord wat die nuwe verhouding beskryf. Die perikoop bestaan uit:

* Die herstel van die kultus (2:18-19).

* Die herstel van die wêreldorde (2:20).

- Die nuwe verhouding met Jahwe (2:21-22).

* Die herstel van die vrugbaarheid (2:23-24).

* Die herstel van die verbond (2:25). 
3:1-5 is ' $n$ profetiese simboliese handeling wat bestaan uit:

* die opdrag (3:1)

* die uitvoering van die opdrag (3:2-3)

" verklaring van die opdrag (3:4-5).

3 Die "kennis" van Jahwe ontbreek (4:1-9:9)

In 4:1-9:9 is daar drie versamelings:

(a) 4:1-5:7 - regsgedinge (uit die jare voor die oorlog)

(b) 5:8-7:16 - die oorlog en daarna (die Siro-Efraimitiese Oorlog)

(c) 8:1-9:9 - kultus, feeste en ballingskap (uit die jare na die oorlog).

Die drie versamelings hou verband met mekaar: Daar is ' $n$ beweging vanaf die aanklagte (die oorsaak) in (a) ${ }^{28}$, deur die oorlog (die gevolg) in (b), na die Assiriese oorheersing (voor die val van Samaria). Die drie dele word verder aan mekaar verbind deurdat die aanspreekvorm deurgaans "Israel" is, en nie "Efraim" soos in 12:1 en 13:1 nie, en deurdat die basiese klag in die hele deel gaan oor die gebrek aan "กYบ Jahwe". Daarteenoor word hierdie uitdrukking eers weer in hoofstuk 13 in hierdie betekenis gebruik ${ }^{29}$. Die tema is dus: Die "kennis" van Jahwe ontbreek.

(a) Die versameling 4:1-5:7 bestaan uit drie regsgedinge wat 'n parallelle opbou vertoon:

- 'n Regsgeding met die inwoners van die land (4:1-3):

die aangeklaagdes (4:1a-b)

die oortredings (4:1c-2)

die oordeel (4:3).

- 'n Regsgeding teen die priesters (4:4-19):

die aangeklaagdes, aanklag en straf (4:4-10)

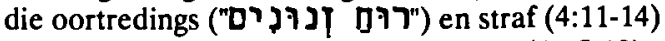

die onomkeerbaarheid van die toestand (4-15-19).

- $\quad$ 'n Regsgeding teen die priesters en leiers (5:1-7):

die aangeklaagdes $(5: 1-2)$

die oortredings ("רךס ונורנים") (5:3-4)

die onomkeerbaarheid van die toestand (5:5-7).

(b) Die versameling 5:8-7:16 begin met 'n oproep om die ramshoring te blaas en eindig met oorlogsverwoesting, terwyl 8:1 opnuut 'n oproep doen om die ramshoring te blaas, waardeur 'n nuwe versameling ingelei word. Die deel gaan oor die SiroEfraimitiese Oorlog en die verwarrende tye wat daarop gevolg het. Dit bestaan uit twee perikope: 
5:8-7:2 gaan oor die oorlog en die onmiddellike gevolge daarvan. Die einde is nie so duidelik nie, maar kan tog herken word uit die gevolgtrekking in 7:2b, ingelui met ig. D. Dit behels die volgende subperikope:

* Die burgeroorlog begin (5:8-11)

- Soek Jahwe se genesing! (5:12-15)

*'n Oproep tot boetedoening (6:1-3)

"Soek Jahwe se 700 en "kennis"! (6:4-6)

" Israel se "siekte" (6:7-7:2).

7:3-16 beskryf die toestand in die land na die oorlog. Dis afgegrens deur 7) 7ר 7:3 en in 7:15 en 16. Dit bestaan uit die volgende subperikope:

* 'n Verradelike binnelandse beleid (7:3-7)

- die metafoor is 'n bakkersoond

- 'n Dwase buitelandse beleid (7:8-12)

- die metafore is 'n roosterkoek en 'n voël

- 'n Bedrieglike godsdienstige beleid (7:13-16).

(c) Die versameling 8:1-9:9 moet teen die agtergrond van die na-oorlogse jare gesien word toe Israel verklein is tot Samaria (8:8), aan Assirië tribuut moes betaal (8:10), en ballingskap 'n werklike bedreiging geword het (9:3-4). Dit bestaan uit twee perikope:

8:1-14 word as 'n eenheid afgebaken deur die volk se opvatting: "ons ken U" in 8:2, en God se teenstellende woorde "Israel het sy Maker vergeet" in 8:14. Ten spyte van die oorlog en ten spyte van die volk se aanspraak dat hulle God "ken", het hulle God "vergeet". Hiervan is hulle verdorwe kultus 'n bewys.

9:1-9 begin met ' $n$ oproep rondom die oesfees, terwyl 9:10 weer ' $n$ nuwe saak inlui, naamlik Israel se verwording sedert die begin van die verhouding tussen Jahwe en Israel. In hierdie perikoop word Israel gewaarsku om nie té vreugdevol oor die oes te wees nie, omdat die ellendes nog lank nie verby is nie: ballingskap wag vir hulle.

4 Die verlore onskuld van Israel se jeug (9:10-11:11)

In 9:10-11:11 word sekere historiese gebeurtenisse aangehaal as vertrekpunt vir die profetiese aankondiging van oordeel. Daarby word bepaalde metafore gebruik om Israel se verhouding tot Jahwe bloot te lè. In die volgende samevatting word eers die metafoor, dan die historiese gebeurtenis(se), vervolgens die oortreding(s), en laastens die oordeel weergegee (let op die parallelle opbou by 9:10-17 en die verrassende wending aan die einde van 11:1-11): 
9:10-17 - druiwe in die woestyn/'n jong palmboom;

Baăldiens by Baäl- Peor/boosheid by Gilgal;

vrugbaarheidskultus/die koning se rol in die kultus;

kinderloosheid en Jahwe se verwerping.

10:1-8 - 'n welige wingerdstok;

die wegvoering van die koning;

valsheid, buitelandse verdrae, onregverdige regspraak;

wegvoering van koning en kalf, verwoesting van altare.

10:9-15 - 'n geleerde vers;

gebeure by Gibea en Bet-Arbel;

vertroue op eie militêre mag; oorlog, verwoesting, dood van die koning.

11:1-11 - 'n kind verlos uit slawerny;

die verlossing uit Egipte en versorging in die woestyn; afgodery; oorlog en slawerny.

Wending: redding uit slawerny.

Elke perikoop teken 'n gunstige beeld van Israel se "jeug", 'n sondige geskiedenis sedertdien, en 'n troostelose toekoms. Die sondes is grotendeels die drie wat deur die hele boek beklemtoon word en wat in 14:4 bely word, naamlik buitelandse bondgenootskappe, vertroue op eie mag, en afgodery. Die verrassende wending aan die einde vorm ' $n$ afsluiting van die hoofdeel wat omskryf kan word met: Die verlore onskuld van Israel se jeug.

$5 \quad$ Die hede in die lig van die verlede (12:1-14:1)

12:1-14:1 word saaklik saamgebind deurdat elke perikoop 'n verband lê tussen die hede en die verlede, en die kontras skets tussen Efraim en Jahwe. In teenstelling met die vorige hoofdeel val die klem hierdie keer egter op historiese persone, eerder as op historiese plekke ${ }^{30}$. Die hoofdeel bestaan uit twee perikope:

12:1-15 beskryf Efraim se bedrog onder meer met verwysing na die Jakobverhaal, terwyl die rol van die profeet as God se instrument teruggevoer word na die uittog.

13:1-14:1 skets Efraim se droewige vooruitsigte teen die agtergrond van 'n trotse verlede, en die Here se sorg van die verlede teenoor sy oordeelsbesluit van die hede.

6 Jahwe, die getroue (14:2-9)

14:2-9 vorm 'n kontras met 1-3 deurdat Israel haar sonde bely en van Jahwe vergifnis ontvang. Die kontras word verder versterk deurdat 'n positiewe omkering

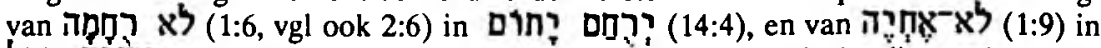

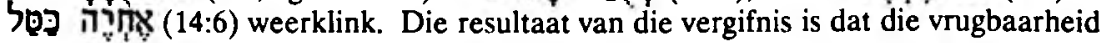


wat hulle voorheen by die Baäls gesoek het, nou by Jahwe gekry word. Die perikoop bestaan uit twee dele:

* 'n Skuldbelydenis in die vorm van 'n boetelied (14:2 4)

* Die vergifnis in die vorm van 'n liefdeslied (14:5-9).

$7 \quad$ Slot $(14: 10)$

14:10 is die afsluiting van die boek waar die leser met terme eie aan die wysheid tot 'n beslissing opgeroep word.

\section{NOTAS:}

1 T Laetsch, Bible commentary. The Minor Prophets, St Louis, Missouri 1956, XIII.

2 H Frey, Das Buch des Werbens Gottes um seine Kirche, Stuttgart 1961, VIXIII.

3 W Rudolph, Hosea, Gütersloh 1966, 26.

4 J L Mays, Hosea. A commentary, London 1969, 15.

5 F I Andersen \& D N Freedman, Hosea A new translation with introduction and commentary, Garden City 1980, 57.

6 H W Wolff, Dodekapropheton 1. Hosea, Neukirchen-Vluyn 1965, XXI.

7 C van Leeuwen, Hosea, Nijkerk 1968, $17-19$ (vergelyk ook 27, 93, 193, 235).

8 A Deissler, Zwölf Propheten. Hosea, Joël, Amos, Würzburg 1981, 10.

9 J Jeremias, Der Prophet Hosea, Göttingen 1983, 18-20.

10 Gale A Lee, Composition and tradition in the book of Hosea, Atlanta 1987, 310.

11 D A Hubbard, Hosea An introduction and commentary, Leicester 1989, 33.

12 D B Wyrtzen, "The Theological Centre of the Book of Hosea", Bibliotheca Sacra 141 (1984), 316.

13 D Stuart, Hosea-Jonah, Waco 1987, 17-19.

14 HD Beeby, Grace Abounding. A commentary on the book of Hosea, Grand Rapids 1989, 47.

15 Mays, $a w, 15$.

$16 \quad$ Stuart, $a w, 8$. 
17 Wolff, $a w, \mathrm{XXIV-XXV}$. Vir 'n oorsig van die verskillende indelingsteorieë, kyk Yee, $a w, 1-25$.

18 Yee, $a w, 310$.

19 Yee, $a w, 309$.

20 Yee, $a w, 47$.

21 Rudolph, $a w, 26$.

22 Wolff, $a w, X I-X I I$.

23 Hubbard, $a w, 33-34$. Sy afbakening van sommige van die versamelings by 33-34 verskil van dié by 96 . Dié by 96 word tussen hakies bygevoeg.

24 Hubbard, $a w, 197$.

25 Vergelyk byvoorbeeld Wyrtzen, Bibliotheca Sacra 141 (1984), 316, wat 'n indeling volg van vyf sikliese bewegings vanaf oordeel na heil, naamlik: 1:2$2: 1 ; 2: 2-23 ; 3: 1-5 ; 4: 4-11: 11 ; 11: 2-14: 8$. Dit is basies dieselfde as die drie groot versamelings, met ' $n$ onderverdeling van die eerste groot versameling.

26 Hierdie standpunt is contra Wolff, $a w 37$, en verskeie ander kommentare.

27 Vergelyk die "laws of chiastic structures", in N W Lund, Chiasmus in the New Testament. A study in Formgeschichte, Chapel Hill, 1942, 40-41. D J Clark, "Criteria for identifying chiasm", Linguistica Biblica 35 (1975), 68, noem dit "double membership".

28 Vergelyk hoe daar telkens terugverwys word na wat in 4:1-5:7 gesê is. Hubbard, $a w, 117$, wys onder meer op die volgende: 4:1-3, 4-19 teenoor 5:1.

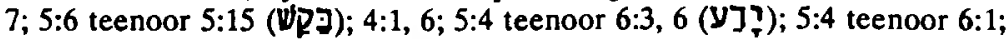

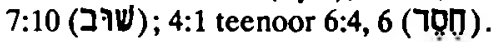

29 In die sin van "kennis" van Jahwe/God, kom dit voor in 4:1; 4:6 (2x); 5:4; 6:3; 6:6; 8:2. Ander betekenisaanwendings van $y$ ? ? in hierdie deel is in 5:3; 7:9 (2x); 8:4; 9:7. Daarteenoor word dit in die sin van die "ken" van Jahwe/God verder net in 2:22; 13:4 en 5 teëgekom, en in 'n ander betekenis in 2:10; 11:3; 14:10.

30 Vergelyk Hubbard, a $w, 198$. 